\title{
Expression of neurotrophic factors by Schwann Cells promotes regeneration of central nervous system
}

\author{
Fausto P. Guzen ${ }^{1,2}$ \& Priscila F. Brito Guzen ${ }^{2}$ \\ ${ }^{1}$ Laboratório de Anatomia Humana, Departamento de Biociências, Universidade Estadual do Rio \\ Grande do Norte - UERN, RN, Brasil, CEP: 59607-360 \\ ${ }^{2}$ Laboratório de Anatomia Humana, Instituto de Ciências da Saúde, Departamento de Anatomia, \\ Faculdade de Enfermagem e de Medicina Nova Esperança - FACENE/FAMENE, Mossoró, RN, \\ Brasil, CEP: 59.628-000
}

\section{Expressão de fatores neurotróficos por células de Schwann promove regeneração do sistema nervoso central}

\begin{abstract}
Schwann cells (SCs) are glial cells originally found in the peripheral nervous system. These cells express many neurotrophic factors, which have many implications on neuronal survival and regeneration, and present receptors to some of these factors suggesting autocrine stimulation to SCs survival, proliferation, differentiation and development. Some of these factors are expressed naturally while others need a traumatic situation and/or axonal contact. The secretion of factors has an important function as mediator of neuron-glial signaling. Many expressions of factors are suppressed in SCs of intact nerves but axonal injury promotes increasing of their synthesis and, yet, production of these factors is suppressed during nerve regeneration. The purpose of this article is to review key studies showing that intracerebral SC grafts limit injury-induced tissue loss and promote axonal regeneration and myelination and that this response can be improved by adding neurotrophic factors. Finally, this review will reflect on the prospect of SCs for repairing the nervous system.
\end{abstract}

Key Words: Schwann cells, neurotrophic factors, nervous system, regeneration.

\section{Introduction}

Schwann cells (SCs) have a great potential for development, maintenance and nervous system repair, since these cells express several neurotrophic factors, as nerve growth (NGF); fibroblastic growth (FGF), insulin growth (IGF), brain derived neurotrophic (BDNF), glial derived neurotrophic factor (GDNF), and many others (Ide, 1996; Tuszynski et al., 1998; Jessen and Mirsky, 1999; Parkinson et al., 2001). These molecules belong to a family of polypeptides that promotes and controls proliferation, differentiation, migration, and survival of their target cells. Moreover, these neurotrophic factors play an important role in the development, maintenance, cellular communication and regeneration of nervous system, required for survival of discrete neuronal populations (Reynolds and Wollf, 1993; Davies, 1998; Frostick et al., 1998; Meier et al., 1999; Weisenhorn et al., 1999; Hildebrand and Lillesaar, 2000; Kinameri and Matsuoka, 2003). During the past three decades, the identification of molecules exhibiting trophic actions has increased drastically.

Trophic factors, in normal intact nerves, are produced and conveyed to the cell body retrogradely and a characteristic important of SCs is that these cells produce neurotrophic factors in both normal and traumatic situations (Ide, 1996; Matsuoka et al., 1997).

Injury of the central nervous system leads to cellular changes not only in the affected neurons but also in adjacent glial cells. This neuroglial activation is a consistent feature in many forms of brain pathology and appears to reflect an evolutionarily-conserved program which plays an important role for neuronal repair (Raivich et al., 1999). This stimulation of glial cell paracrines trophic events in the central and peripheral nervous system, probably by triggering the expression of GDNF (Benveniste, 1992; Raivich et al., 1999; John et al., 2003).

\section{Schwann cells and expression of neurotrophic} factors 
This study suggests that soluble molecules (neurotrophic factors), released by SC into medium, are able to increase neuronal trophism in culture. It is possible that $\mathrm{SC}$ conditioned medium (SCCM) may promote neuronal development, survival or act as a neuronotrophic factor and attract a growing or regenerating axon down a myelin sheath. This finding, together with our previous report that SCCM contains an NGF-like molecule (Frostick, et al., 1998), supports the hypothesis that the SC synthesizes several target-specific neurotrophic factors (Assouline et al., 1987). Collier and Martin (1993) suggested that a diffusible product, or combination of products, derived from SC activated by nerve explantation, influences embryonic dopamine neurons to promote cell survival and neurite extension by these cells.

Neurotrophic factors like Basic FGF is a multifunctional polypeptide, which acts on a variety of cell types of mesodermal origin (Gospodarowiez et al., 1987). Studies have showed that basic FGF and acidic FGF are mainly located in the SCs: acidic FGF was primarily found in the cytoplasm while basic FGF was predominantly found in the nuclei (Neuberger and De Vries, 1993). SCs exhibited increased FGF immunoreactivity with increased time in culture. However, neurotrophic factor expression is important for promoting regeneration of the central nervous system (Kayton and Aktas, 2000).

Expression of neuregulin (NRG) protein has showed constitutive activation of a neuregulin receptor, suggesting the existence of an autocrine loop involving NRG in SC promoting proliferation and survival of SCs. These results suggest that SCs switch their survival dependency around the time of birth from axonal signals such as NRG to autocrine signals (Rosenbaum et al., 1997; Cheng et al., 1998; Syroid et al., 1999; Mirsky et al., 2002).

NRG appears to be involved in the control of cell survival, proliferation, and differentiation, as well as of gene expression at different levels of the pathways, and their evolving roles in peripheral and central nervous system development (Topilko et al., 1996; Syroid et al., 1999). NGRs are present in neuronal cells in which they act as mediators of neuron-glial signaling (Raabe et al., 1996), a crucial function for peripheral nerve development and regeneration (Mahanthappa et al., 1996).

BDNF mRNA was expressed in SCs in the distal segment of lesioned nerve and in the denervated muscle fibers (Chan et al., 2001). Thus, SCs and denervated muscle fibers may contribute to the sources of BDNF during regeneration (Zhang et al., 2000). Similarly, Namiki et al (2000) observed that invasion and proliferation of SCs were more prominent at the injury site in the BDNF-treated animals than in the others groups.

\section{Neurotrophic factors and neuronal trophism in vitro}

Based upon the model of study of SC-spinal anterior horn neuron co-cultivation separated by glass coverslip, Wu and Zhu (1996) confirmed that $\mathrm{SC}$ can secrete a neuron survival promoting factor and a neurite outgrowth promoting factor. Ard et al (1987) also confirmed either SC surface or the ectracellular matrix produced and assembled by SC in order to promote neurite outgrowth and to guide outgrowth from several types of peripheral and central nervous system neurons studied (from foetal rat dorsal root ganglia, foetal rat superior cervical ganglia, somatosensory cortex of embryonic rats).

The neurotrophins (NT) play multiple roles in the developing nervous system, including growth, cell survival, differentiation and myelination (Menei et al., 1998; Chan et al., 2001; Cosgaya et al., 2002; Peng et al., 2003; Yamauchi et al., 2003).

Franke et al (2000) observed that the neurotrophin BDNF and neurotrophin-3 (NT-3) showed survival function, promoting effects on dopaminergic neurons. This function is induced upon simultaneous depolarization of cultured mesencephalic cells with NMDA or upon activation of cAMP/PKA-dependent, signaling pathways with dibutyryl cAMP, BDNF, and GDNF. cAMP produces convergent signal to activate protein kinase $\mathrm{A}$ and mitogen-activated protein kinase pathways which are involved in the survival of postnatal mesencephalic dopamine neurons in vitro (Lara et al., 2003).

In order to investigate the effects of the high molecular weight basic FGF isoforms $(21,000 \mathrm{~mol}$. wt, 23,000 mol. wt) on dissociated rat mesencephalic dopaminergic neurons, Grothe et al (2000) prepared a recombinant basic FGF (prepared in a histidine expression system) and administered it on dopaminergic neurons in vitro. SCs, overexpressing the high molecular weight isoforms, were co-cultured with dopaminergic neurons. Exogenous high molecular weight basic FGF isoforms stimulated the survival of embryonic mesencephalic dopaminergic neurons and protected them from neurotoxicity by 6-hydroxydopamine. Co-culture of dopaminergic neurons with high molecular weight basic FGF over-expressing SC revealed an increased survival and neurite formation of the mesencephalic dopaminergic neurons, even compared with exogenous administration of basic FGF isoforms.

In the study realized by Peng et al (2003), cultured Xenopus spinal cord neurons were treated 
with a mixture of BDNF, GDNF, NT-3, and NT-4, in addition to forskolin and IBMX or the cellpermeant form of cAMP, to elevate the cAMP level. The authors observed that outgrowth and survival of neurons were dramatically increased by this trophic stimulation, however, when these neurons were cocultured with muscle cells, the trophic agents resulted in a failure of synaptogenesis. Induction of ACh receptor (AChR) clustering in cultured muscle cells was inhibited at nerve-muscle contacts, in sharp contrast to control, untreated cocultures, because AChR clustering induced by agrin or growth factor-coated beads in muscle cells was unaffected by trophic stimulation. In the control, again was deposited along the neurite and at nerve-muscle contacts, and this was significantly downregulated in cultures treated with trophic stimuli. The analysis by reverse transcriptase polimerase chain reaction showed that this decrease in agrin deposition was caused by an inhibition of agrin synthesis by trophic stimuli. Both agrin synthesis and induction of AChR clustering were restored under trophic stimulation when SCCM was introduced. The authors suggest that trophic stimulation maintains spinal neurons in the growth state, and SC derived factors allow them to switch to the synaptogenic state.

Axon growth to peripheral and central nervous system targets encompasses elongation, intestinal branching, fasciculation/defasciculation, terminal branching and increasing axon caliber, all of which are presumably influenced by extracellular signals. At present, it is unknown whether different factors regulate distinct morphological features or whether the same factors produce different effects as development progresses. NGF, for example, induces growth of sparsely branched sensory axons in vitro at embryonic day 13 (Lent et al., 1999), but highly branched axons in dorsal root ganglion neurons cultured from adult animals (Cafferty et al., 2001).

Macrophages conditioned medium contains some factors, which can promote NGF secretion in rat SC in vitro, suggesting that macrophages regulates NGF secretion by secreting certain cytokines (Ma et al., 1998). SC cultured in presence or not of inflammatory cytokines can secrete neurons survival promoting factor and a neurite outgrowth promoting factor, which undoubtedly plays a crucial role in regeneration of nervous system.

Torres et al (2002) studied the effect of sciatic conditioned medium (SCM) on rat retinal cells maintained in culture. The treatment with SCM obtained after 14 days in vitro induced a three-fold increase in protein content of the culture after 48 hours in vitro and this value remained equally high up to 72 hours. After treatment with SCM for 48 hours, there was an increase of $\sim 50 \%$ in the number of processes of longer cellular body. After 72 hours of treatment with SCM, the authors observed a significant increase $(\sim 160 \%)$ in the number of processes smaller cellular body and an increase of $190 \%$ in the number of cells presenting processes of longer cellular body, always in comparison with control cultures. As evaluated by morphological criteria, SCM increased cell adhesion, neuronal survival and glial cell proliferation (Torres et al., 1998).

It is important to determine whether transforming growth factor $\beta$ enhances extracellular matrix production by $\mathrm{SC}$ in vitro, and whether it can stimulate expression of myelin-specific proteins such as $\mathrm{P}_{0}$ and myelin basic proteins. Cytokines could play a specific role in controlling SC function in vivo, both stimulating proliferation and concomitantly promoting synthesis of differentiation-specific extracellular matrix molecules. Such a role would be relevant to peripheral nerve regeneration after wounding, and also to the development of nerve tracts during embryogenesis.

Insulin growth factor (IGF) is an additional trophin that can promote $\mathrm{SC}$ survival in vitro and protects IGFBP-5 in SC-conditioned medium from proteolysis (Meier et al., 1999; Cheng et al., 1999; Syroid et al., 1999). In vitro, IGF-I promotes mitogenesis and differentiation of SCs and, the last one, may occur in part by enhancing IGFBP-5 expression via phosphatidylinositol-3 kinase activation (Cheng et al., 1996; Cheng and Feldman, 1997; Cheng et al., 1999).

Plaquet derived growth factor (PDGF) is an important component of this autocrine survival signal in SCs and it is a potent mitogen for SCs with addition of forskolin for stimulating DNA synthesis and increasing cell number (Davis and Stroobant, 1990; Watabe et al., 1994; Meier et al., 1999; Oya et al., 2002).

SC precursor cells express TrkC and PDGF receptors alpha and beta and TrkC-ligand NT-3 and can act synergistically to potentiate the effect of PDGF, suggesting that a combination of growth factors are acting in concert and in synergy to regulate early SC development (Eccleston et al., 1990; Lobsiger et al., 2000).

\section{Schwann cells and regeneration of central nervous system}

As discussed above, in experimentally injured central nervous system, implantation of SCs fills the cavity, limits further tissue loss, and promotes regeneration of severed axons (Martin et al., 1996; 
Takami et al., 2002; Azanchi et al., 2004). Currently, additional interventions have been explored in order to understand added effects to the SC-mediated regeneration response. SCs are capable of myelinating central axons that have grown into the graft. However, it needs to be kept in mind that implanted SCs do not migrate into the surrounding adult spinal nervous tissue and, therefore, can not be expected to myelinate axons that have regenerated through and beyond the graft. It is imperative to also develop strategies that will rescue oligodendrocytes from dying following spinal cord injury.

An important advantage of SCs over other cell types for implantation approaches is their ability to myelinate central axons. This possibility along with the neuroprotective and regenerative abilities of SCs has established them as strong candidates for clinical cell-based repair strategies. SC implantation into the contusion lesion results in a neuroprotective effect, which might indirectly be responsible for the observed improvements in the axonal and behavioral response. Recently, in an effort to profit more from neuroprotective effects, in the moderately lesioned central nervous system, acute administration of two well-known neuroprotective agents, methylprednisolone and interleukin 10, was combined with a 7-day delayed implantation of SC (Pearse et al., 2004). This study demonstrated that this combination improved tissue sparing over the individual treatments but the overall functional improvements were largely similar between treatments or in some cases worse. Unfortunately, it has not been determined whether this approach individually or in combination caused either axonal sparing and/or axonal regeneration.

The incompleteness of contusive injuries makes it difficult to distinguish between spared and regenerated axons. The only reliable approaches ought to involve double-neuronal tracing techniques or time course studies are both technically demanding and labor intensive. From many experimental studies it has become clear that in the case of a compression injury, a combining strategy will be needed which includes the implantation of a cellular substrate to fill the cavity in order to promote axonal growth across and beyond the injury towards the lower areas of the cord that contain the neurons involved in motor function. For optimal functioning of these circuits, some regenerated axons may need to be myelinated. It is very likely that these newly formed axonal circuits are not identical to the original ones (Bareyre et al., 2004), and additional rehabilitative therapies will be required to obtain biologically significant motor recovery that involves these new connections.

\section{Conclusion}

Several issues need careful consideration before SC implantation strategies will become a legitimate option for repair strategies of the injured human spinal cord. The benefits of the procedure should outweigh the risks and the grafting technique should be safe and not exacerbate the neurological deficit. For this, visualization of the shape and dimensions of the lesion using magnetic resonance imaging before implantation could be advantageous. In general, any implantation strategy should not evoke immunological and/or inflammatory reactions. With SCs this can be accomplished since they would permit autologous implantation thereby avoiding such reactions as well as the use of immunosuppressant drugs, such as cyclosporine-A, to prevent graft rejection. Autologous implantation can be performed by harvesting the SCs from a piece of peripheral nerve from the patient. The removal of a piece of a sensory nerve, such as the sural or saphenous nerve, may be preferred over removal of a piece of a motor nerve to avoid additional loss of motor function. Also, the option for autologous implantation avoids ethical issues raised by the use of fetal tissue or embryonic stem cells.

For repairing of some cord injuries, one could envisage that a large number of SCs will be necessary. Because SCs can be cultured in vitro with the help of mitogens large enough numbers can be obtained for implantation. One should be aware, though, that many divisions can induce the formation of malignant cells. This has not been observed following multiple divisions of SCs in vitro. Another concern that has not yet been fully addressed in experimental studies is that mitogeninduced division may change the neuroprotective and regenerative abilities of SCs.

Taking all this in consideration, autologous implantation of SCs into the injured central nervous system has a future in clinical application. From experimental studies, many of which presented in this review, it has become clear that grafting SCs alone will not result in substantial functional recovery. Additional interventions and/or rehabilitative treatments need to be part of an SCbased repair strategy. These additional treatments need to be identified before autologous SC implantation aimed at repairing the injured spinal cord will become a reality.

Despite the progress outlined above, several key issues remain to be addressed before we can claim a comprehensive understanding of the biological functions of neurotrophic factor-induced axon growth or the signaling mechanisms it involves. We are just beginning to identify transcription factors activated by neurotrophic factors that are critical for 
axon growth. It is certain that the use of expression profiling technology will greatly increase knowledge in this area. Eventually, newly transcribed proteins and signaling pathways must converge to regulate the cytoskeleton. However, surprisingly little is known about the links between neurotrophic factor signaling and the regulation of cytoskeletal proteins.

\section{Referências}

Ard, M. D., Bunge, R.P., Bunge, M.B. (1987). Comparison of the Schwann cell surface and Schwann cell extracellular matrix as promoters of neurite growth. Journal Neurocytology, 16(4), 539-55.

Assouline, J.G., Bosch, P., Lim, R., Kim, I.S., Jensen, R., Pantazis, N.J. (1987). Rat astrocytes and Schwann cells in cultured synthesize nerve growth factor-like neurite-promoting factors. Brain Research, 428, 103-118.

Azanchi, R., Bernal, G., Gupta, R., Keirstead, H.S. (2004). Combined demyelination plus Schwann cell transplantation therapy increases spread of cells and axonal regeneration following contusion injury. Journal of Neurotrauma, 21, 775-788.

Bareyre, F.M., Kerschensteiner, M., Raineteau, O., Mettenleiter, T.C., Weinmann, O, Schwab, M.E. (2004). The injured spinal cord spontaneously forms a new intraspinal circuit in adult rats. Nature Neuroscience, 7(3), 269-77.

Benveniste, E. N. (1992). Inflammatory cytokines within the central nervous system: sources, function, and mechanism of action. American Journal of Physiology, 263(1), C1-16.

Cafferty, W. B., Gardiner, N. J., Gavazzi, I., Powell, J., McMahon, S. B., Heath, J. K., Munson, J., Cohen, J., Thompson, S. W. (2001). Leukemia inhibitory factor determines the growth status of injured adult sensory neurons. Journal of Neuroscience, 21, 7161-7170.

Chan, J. R., Cosgaya, J. M., Wu, Y. J., Shooter, E. M. (2001). Neurotrophins are key mediators of the myelination program in the peripheral nervous system. Proceedings of the National Academy of Sciences of the United States of America, 98(25), 14661-14668.

Cheng, H. L., Randolph, A., Yee, D., Delafontaine, P., Tennekoon, G., Feldma, E. L. (1996). Characterization of insulin-like growth factor-I and its receptor and binding proteins in transected and cultured Schwann cells. Journal Neurochemistry, 66(2), 525-536.

Cheng, H. L., Feldman, E. L. (1997). Insulin-like growth factor-I (IGF-I) and IGF binding protein5 in Schwann cell differentiation. Journal of
Cell Physioogyl, 171(2), 161-167.

Cheng, L., Esch, F.S., Marchionni, M.A., Mudge, A.W. (1998). Control of Schwann cell survivel and proliferation: autocrine factors and neuregulins. Molecular and Cellular Neuroscience, 12, 141-156.

Cheng, H. L; Shy, M., Feldman, E. L. (1999). Regulation of insulin-like growth factor-binding protein-5 expression during Schwann cell diferentiation. Endocrinology, 140(10), 44784485.

Collier, T. J., Martin, P.N. (1993). Schwann cells as a source of neurotrophic activity for dopamine neurons. Experimental Neurology, 124(1), 12933.

Cosgaya, J. M., Chan, J. R., Shooter, E. M. (2002). The neurotrophin receptor $\mathrm{p} 75 \mathrm{NTR}$ as a positive modulator of myelination. Science, 298(5596), 1245-1248.

Davis , J. B., Stroobant, P. (1990). Platelet-derived growth factors and fibroblast growth factors are mitogens for rat Schwann cells. Journal of Cell Biology, 110(4): 1353-1360.

Davies, A. M. (1998). Neuronal survival: Early dependence on Schwann cells. Current biology, 8(1), R15-18.

Eccleston, P.A., Collarini, E.J., Jessen, K.R., Mirsky, R., Richarrdson, W.D. (1990). Schwann cells secrete a PDGF-like factor: Evidence for an autocrine growth mechanism involving PDGF. European Journal of Neuroscience, 2, 985-992.

Franke, B., Bayatti, N et al. (2000). Neurotrophins require distinct extracellular signals to promote the survival of CNS neurons in vitro. Experimental. Neurology, 165(1), 125-35.

Frostick, S.P., Yin, Q., Kemp, G.J. (1998). Schwann cells, neurotrophic factors, and peripheral nerve regeneration. Microsurgery, 18(7), 397-405.

Gospodarowiez, D., Ferrara, N., Schweigerer, L., Neufeld, G. (1987). Structural characterization and biological functions of fibroblastic growth factor. Endocrinology Review, 8, 95-114.

Grothe, C., A. Schulze, et al. (2000). The high molecular weight fibroblast growth factor-2 isoforms $(21,000 \mathrm{~mol}$. wt and 23,000 mol. wt) mediate neurotrophic activity on rat embryonic mesencephalic dopaminergic neurons in vitro. Neuroscience, 100(1), 73-86.

Hildebrand, C., Lillesaar, C. (2000). Schwann cells promote development and repair of nerve cells. Lakartidningen, 97(26-27), 3168-3173.

Ide, C. (1996). Peripheral nerve regeneration. Neuroscience Research, 25, 101-121.

Jessen, K. R., Mirsky, R. (1999). Why do Schwann cells survive in the absence of axons? Annals of 
the New York Academy of Sciences, 14(883), 109-115.

John, G. R., Lee, S.C., Brosnan, C.F. (2003). Cytokines: Powerful regulators of glial cell activation. Neuroscientist, 9(1), 10-22.

Kayton, R.J., Aktas, R.G. (2000). Electron microscopic immunolocalization of basic fibroblast growth factor in peripheral nerves. Histochem Cell Biology. 114, 413-419.

Kinameri, E., Matsuoka, I. (2003) Autocrine action of BMP2 regulates os GDNF-mRNA in sciatic Schwann cells. Molecular Brain Research, 117, 221-227.

Lara, J., Kusano, K., House., S., Gainer, H. (2003). Interactions of cyclic adenosine monophosphate, brain-derived neurotrophic factor, and glial cell line-derived neurotrophic factor treatment on the survival and growth of postnatal mesencephalic dopamine neurons in vitro. Experimental Neurology, 180(1), 32-45.

Lent, S. I; Kundson, C. M; Korsmeyer, S. J., Snider, W. D. (1999). Neurotrophins support the development of diverse sensory axon morphologies. Journal of Neuroscience, 19, 1038-1048.

Lobsiger, C. S; Schweitzer, B; Taylor, V., Suter, U. (2000). Plateled-derived growth factor- $\beta$ supports the survival of cultured rat Schwann cell precursors in synergy with neurotrophin-3. Glia, 30(3), 290-300.

Ma, X., Yu., Y., Zhong., S. (1998). [The effect of the macrophages conditioned media(MOCM) on NGF secretion in newborn rat schwann cells in vitro]. Zhonghua Wai Ke Za Zhi, 36(2), 80-82.

Mahanthappa, N.K., Anton, E.S., Matthew, W.D. (1996). Glial growth factor 2, a soluble neuregulin, directly increases Schwann cell motility and indirectly promotes neurite outgrowth. Journal of Neuroscience, 16, 46734683.

Martin D, Robe P, Franzen R, Delree P, Schoenen J, Stevenaert A., Moonen, G. (1996). Effects of Schwann cell transplantation in a contusion model of rat spinal cord injury. Journal of Neuroscience Research, 45, 588-597.

Matsuoka, I; Nakane, A., Kurihara, K. (1997). Induction of LIF-mRNA by TGF-beta 1 in Schwann cells. Brain Research, 776(1-2), 170180.

Meier, C., Parmantier, E., Brennan, A., Mirsky, R., Jessen, K.R. (1999). Developing Schwann cells acquire the ability to survive without axons by establishing and autocrine circuit involving insulin-like growth factor, neurotrophin-3, and platelet-derived growth factor-BB. Journal of Neuroscience, 19, 3847-3859.
Menei, P., Menei-Montero, C., Whittemore, S.R., Bunge, R.P., Bunge, M.B. (1998). Schwann cells genetically modified to secrete human BDNF promote enhanced axonal regrowth across transected adult rat spinal cord. European Journal of Neuroscience, 10, 607-621.

Mirsky, R., Jessen, K. R., Brennan, A., Parkinson, D., Dong, Z., Meier, C., Parmantier, E., Lawson, D. (2002). Schwann cells as regulators of nerve development. Journal Physiology Paris, 96(1-2), 17-24.

Namiki, J., Kojima, A., Tator, C. H. (2000). Effect of brain-derived neurotrophic factor, nerve growth factor, and neurotrophin-3 on functional recovery and regeneration after spinal cord injury in adult rats. Journal of Neurotrauma, 17(12): 1219-31.

Neuberger, T. J., De Vries, G. H. (1993). Distribution of fibroblast growth factor in cultured dorsal root ganglion neurons and Schwann cells. I. Localization during maturation in vitro. Journal Neurocytology, 22(6),436-48.

Oya, T., Zhao, Y.L., Takagawa, K., Kawaguchi, M., Shirakawa, K., yamauel, T., Sasahara, M. (2002). Plated-derived growth factor-b induced after rat peripheral nerve injuries. Glia, 38(4), 303-312.

Parkinson, D. B., Dong, Z., Bunting, H., Whitfield, J., Meier, C., Marie, H., Mirsky, R., Jessen, K. R. (2001). Transforming growth factor beta (TGF beta) mediates Schwann cell death in vitro and in vivo: examination of c-Jun activation, interactions with survival signals, and the relationship of TGF beta-mediated death to Schwann cell differentiation. Journal of Neuroscience, 21(21): 8572-8585

Pearse, D.D., Marcillo, A.E., Oudega, M., Lynch, M.P., Wood, P.M., Bunge, M.B. (2004). Transplantation of Schwann cells and olfactory ensheathing glia after spinal cord injury: does pretreatment with methylprednisolone and interleukin-10 enhance recovery? Journal of Neurotrauma, 21, 1223-1239.

Peng, H.B., Yang, J.F., Dai, Z., Lee, C.W., Hung, H.W, Feng, Z.H., Ko, C.P. (2003) Differential effects of neurotrophins and Schwann cellderived signals on neuronal survival? Growth and synaptogenesis. Journal of Neuroscience, 23, 5050-5060.

Raabe, T.D., Clive, D.R., Neuberger, T.J., Wen, D., Devries, G.H. (1996) Cultured neonatal Schwann cells contain and secrete neuregulins. Journal of Neuroscience Research, 46, 263-270.

Raivich, G., Jones, L.L., Werner, A., Bluthmann, H., Doetschmann, T., Kreutzberg, G.W. (1999). Molecular signals for glial activation: pro- and 
anti-inflammatory cytokines in the injured brain. Acta Neurochirurgica Supplement, 73, 21-30.

Reynolds, M. L., Woolf, C. J. (1993). Reciprocal Schwann cell-axon interactions. Current opinion in neurobiology, 3(5), 683-693.

Rosenbaum, C., Karyala, S., Marchionni, M.A., Kim, H.A., Krasnoselsky, A.L., Happel, B., Isaacs, I., Brackernbury, R., Ratner, N. (1997) Schwann cells express NDF and SMDF/n-ARIA mRNAs, secrete neuregulin, and show constitutive activation of erbB3 receptors evidence for a neuregulin autocrine loop. Experimental Neurology, 148, 604-615.

Syroid, D.E., Zorick, T.S., Arbet-Engels, C., Kilpatrick, T.J., Eckhart, W., Lemke, G. (1999) A role for insulin-like growth factor-I in the regulation of Schwann cell survival. Journal of Neuroscince, 19, 2059-2068.

Takami T, Oudega M, Bates M.L, Wood P.M, Kleitman N., Bunge M.B. (2002). Schwann cell but not olfactory ensheathing glia transplants improve hindlimb locomotor performance in the moderately contused adult rat spinal cord. Journal of Neuroscience, 22, 6670-6681.

Topilko, P., Murphy, P., Charnay, P. (1996). Embryonic development of Schwann cells: multiple roles for neuregulins along the pathway. Molecular and Cellular Neurosciences, 8, 71-75.

Torres, P.M., Guilarducci, C.V., Araujo, E.G. (1998). Effects of sciatic-conditioned medium on neonatal rat retinal cells in vitro. Brazilian Journal of Medical Biology Research, 31(11), 1439-1442.

Torres, P.M., Guilarducci, C.V., Franco, A.S., Araujo, E.G. (2002). Sciatic conditioned medium increases survival, proliferation and differentiation of retinal cells in culture. International Journal of Developmental Neuroscience, 20(1), 11-20.

Tuszynski, M.H., Weidner, N., Mccormack, M., Miller, I., Powell, H., Conner, J. (1998). Grafts of genetically modified Schwann cells to the spinal cord: survival, axon growth, and myelination. Cell Transplantation, 7(2), 187196.

Watabe, K., Fukuda, T., Tanaka, J., Toyohara, K., Sakai, O. (1994). Mitogenic effects of plateledderived growth factor, transforming growth factor-beta, and heparin-binding serum factor for adult mouse Schwann cells. Journal of Neuroscience Research, 39(5), 525-34.

Weisenhorn, D.M., Roback, J., Young, A.N., Wainer, B.H. (1999). Cellular aspects of trophic actions in the nervous system. International Review of Cytology, 189, 177-265.
Wu, B., Zhu, J. (1996). Neurotrophic effects of Schwann cells in culture on spinal anterior horn neurons. Chinese Medical Journal, 109(7), 54750.

Yamauchi, J., Chan, J.R., Shooter, E.M. (2003). Neutrophin 3 activation of $\mathrm{TrkC}$ induces Schwann cell migration through the c-Jun Nterminal kinase pathway. Proceedings of the National Academy of Sciences of the United States of America, 100(24), 14421-14426.

Zhang, J.Y., Luo, X.G., Xian, C.J., Liu, Z.H., Zhou, X.F. (2000). Endogenous BDNF is required for myelination and regeneration of injured sciatic nerve in rodents. European Journal of Neuroscience, 12(12), 4171-4180.

\section{Endereço para correspondência:}

Fausto Pierdoná Guzen

Avenida Presidente Dutra, 701, Alto de São Manoel, Mossoró, RN.

CEP 59.628-000

e-mail: fauguzen@usp.br

Submetido: 01 de outubro de 2007. Revisado: 30 de Abril de 2008. Aceito: 11 de Maio de 2008. 